\title{
The importance of PET/CT in the evaluation of patients with Ewing tumors"
}

\author{
A importância da PET/CT na avaliação de pacientes com tumores de Ewing
}

\author{
Júlio Brandão Guimarães ${ }^{1}$, Letícia Rigo ${ }^{2}$, Fabio Lewin $^{3}$, André Emerick ${ }^{4}$
}

Guimarães JB, Rigo L, Lewin F, Emerick A. The importance of PET/CT in the evaluation of patients with Ewing tumors. Radiol Bras. 2015 Mai/Jun; 48(3):175-180.

Abstract The effective evaluation for the treatment of patients with Ewing tumors depends on the accuracy in the determination of the primary tumor extent and the presence of metastatic disease. Currently, no universally accepted staging system is available to assess Ewing tumors. The present study aimed at discussing the use of PET/CT as a tool for staging, restaging and assessment of therapeutic response in patients with Ewing tumors. In spite of some limitations of PET/CT as compared with anatomical imaging methods, its relevance in the assessment of these patients is related to the capacity of the method to provide further physiological information, which often generates important clinical implications. Currently, the assessment of patients with Ewing tumor should comprise a study with PET/CT combined with other anatomical imaging modalities, such as radiography, computed tomography and magnetic resonance imaging.

Keywords: Ewing sarcoma; Imaging diagnosis; Diagnosis; Evaluation.

Resu mo A avaliação eficaz para o tratamento dos pacientes com tumores de Ewing depende de uma avaliação precisa da extensão do tumor primário e da existência de doença metastática. Atualmente, não há sistema de estadiamento universalmente aceito para a avaliação dos tumores de Ewing. O presente estudo tem como objetivo discutir o uso da PET/CT como ferramenta para a realização de estadiamento, reestadiamento e avaliação da resposta terapêutica em pacientes com tumores de Ewing. Embora a PET/CT apresente algumas limitações em comparação com os métodos de imagens anatômicos, a importância do exame na avaliação desses pacientes decorre de sua capacidade de fornecer informações adicionais fisiológicas, o que muitas vezes gera implicações clínicas importantes. A avaliação atual dos pacientes com tumor de Ewing deve ser composta do estudo com PET/CT combinado com as outras modalidades de imagem anatômica, como radiografia, tomografia computadorizada e ressonância magnética.

Unitermos: Sarcoma de Ewing; Diagnóstico por imagem; Diagnóstico; Avaliação.

\section{INTRODUCTION}

The Ewing's tumors family is constituted by small blue round cell neoplasms and comprise the Ewing's bone tumor (or Ewing's sarcoma); extraosseous Ewing's sarcoma (a tumor that affects soft tissues); primitive neuroectodermal tumor; and Askin's tumor (primitive neuroectodermal tumor of the chest wall). Typically, such tumors develop in bone structures and soft tissues in children and adolescents between the ages of 11 and 20 years $^{(1)}$.

* Study developed at Hospital São José - Beneficência Portuguesa de São Paulo, São Paulo, SP, Brazil.

1. MD, Radiologist at Medimagem, Physician Assistant at Musculoskeletal Unit, Hospital São José - Beneficência Portuguesa de São Paulo, Collaborator and Fellow at Musculoskeletal Unit, Department of Imaging Diagnosis - Escola Paulista de Medicina da Universidade Federal de São Paulo (EPM-Unifesp), São Paulo, SP, Brazil.

2. MD, Nuclear Medicine Specialist at Medimagem, Physician Assistant at PET/CT Unit, Hospital São José - Beneficência Portuguesa de São Paulo, São Paulo, SP, Brazil.

3. MD, Radiologist at Medimagem, Physician Assistant at PET/CT Unit, Hospital São José - Beneficência Portuguesa de São Paulo, São Paulo, SP, Brazil.

4. MD, Radiologist at Medimagem, Physician Assistant at Musculoskeletal Unit, Hospital São José - Beneficência Portuguesa de São Paulo, São Paulo, SP, Brazil.

Mailing Address: Dr. Júlio Brandão Guimarães. Rua Visconde da Luz, 60, ap. 31, Itaim. São Paulo, SP, Brazil, 04537-070. E-mail: juliobrandaoguimaraes@hotmail.com.

Received August 19, 2013. Accepted after revision April 10, 2014.
Among all primary tumors of the musculoskeletal system, Ewing's tumors present the worst prognosis, although in the recent years chemotherapy with multiple drugs, as well as treatment with combined chemotherapy, radiotherapy and surgery have provided a significant increase in survival of affected patients.

Despite the advances in therapeutics, the prognosis for patients with disseminated primary disease continues to be unfavorable. The survival of patients with lung metastasis is $<40 \%$, while for those patients with bone metastasis and bone marrow infiltration, the survival is not $>20 \%{ }^{(1)}$. Therefore, metastasis detection and detailed staging are essential for treatment planning and therapeutic response prediction.

Until recently, staging has been done by means of noninvasive imaging methods, such as computed tomography $(\mathrm{CT})$ and magnetic resonance imaging (MRI), both presenting with limitations in the differentiation between viable, residual and necrotic neoplastic tissues.

On the other hand, computed tomography in association with positron-emission tomography (PET/CT) has been utilized as a powerful tool to allow for such a differentiation with high sensitivity and specificity, since it is a hybrid method, providing anatomical detailing of the lesions and glycolytic metabolism evaluation (habitually increased in 
such lesions). In addition, one proposes that the degree of 18-fluorodeoxyglucose $\left({ }^{18}\right.$ F-FDG $)$ uptake by Ewing's tumors may have a prognostic value, predicting the patient's response to treatment and indicating the initial stage of the disease.

The present study is aimed at discussing the utilization of PET/CT as a useful and important tool in staging, restaging and evaluation of the therapeutic response in patients with Ewing's tumor.

\section{PET/CT IN THE STAGING OF EWING'S TUMORS}

An effective evaluation for treatment of patients with Ewing's tumor depends upon an accurate assessment of the primary tumor extent and of the presence of metastatic disease. Metastatic dissemination of Ewing's tumors occurs mainly by hematogenous pathway. Common sites of involvement include lungs and the bone marrow ${ }^{(2,3)}$. Bone involvement is most commonly observed in the pelvis $(26 \%)$, femur $(20 \%)$, tibia and fibula $(18 \%)$, chest wall (16\%), upper limbs $(9 \%)$ and spine $(6 \%)^{(1)}$.

Currently, there is not a universally accepted staging system for the evaluation of the Ewing's tumors. Due to its capability of outlining the margins of the viable tumor, which many times may be difficult to differentiate from anatomical distortion or from peritumoral edema at MRI, PET/CT scan as a complement to MRI is extremely useful in the surgical planning and many times it does change the approach to be adopted in such cases.

It has been demonstrated that the PET/CT helps in determining the presence and extent of sarcomas and may allow for the estimation of the histological stage of such tumors ${ }^{(4)}$.

The measured standard uptake value (SUV) of a sarcoma has been utilized to predict the therapeutic response both before and after neoadjuvant therapy, and such SUV is an independent and significant predictor of survival of patients in general; additionally, it allows for the identification of the areas with greater biological productivity within the lesion, guiding biopsies, thus reducing the probability of tumor grade underestimation and consequential adoption of inappropriate approach $^{(4)}$.

Several studies have highlighted the PET/CT advantages, in comparison with conventional imaging methods (MRI, CT and scintigraphy), in the detection of both bone and lymphatic metastases.

PET/CT and other conventional imaging methods can detect practically $100 \%$ of the primary tumors. However, a study has demonstrated that PET/CT was superior in the detection of lymph node metastases (sensitivity of $90 \%$ versus $25 \%$ respectively) and bone metastases (sensitivity of $90 \%$ versus $57 \%)^{(5)}$. In cases of Ewing's sarcoma, the superiority of PET/CT over bone scintigraphy in the detection of bone metastases was significant (sensitivity of $88 \%$ versus $37 \%$, respectively) $)^{(5)}$.

The higher sensitivity of PET/CT, as compared with bone scintigraphy in the detection of bone metastases is presumably due to the direct capability of PET/CT to identify lesions on the basis of the increased metabolic activity neoplastic cells; on the other hand, bone scintigraphy identifies the lesions indirectly based on bone remodeling and repair (osteoblastic activity).

That is particularly important in Ewing's sarcoma metastasis, which is typically mediated by the osteoclasts with bone destruction. On the other hand, PET/CT is not significantly superior to scintigraphy in the detection of osteosarcoma metastasis, presumably on account of the osteoid-producing osteoblastic activity ${ }^{(5)}$.

It has been suggested that investigation with PET/CT may be indicated for detecting skip lesions, whose differentiation from physiological medullary hematopoiesis is difficult at MRI, which is particularly true in the childhood as the physiological hematopoietic medulla may be quite extensive ${ }^{(6)}$.

Figures 1, 2 and 3 show PET/CT images of patients with Ewing's sarcoma.

\section{EVALUATION OF THERAPEUTIC RESPONSE OF EWING'S TUMORS BY PET/CT}

Chemotherapy is the initial treatment of both localized and metastatic Ewing's tumors. For initial disease, the treatment is aimed at cytoreduction in order to avoid the development of micrometastases and for a more appropriate local management ${ }^{(1)}$. After chemotherapy, a local surgical treatment or radiotherapy is performed. For those patients with exclusively pulmonary metastatic disease, or those with few metastases, surgical resection of the primary lesion and metastases is indicated after chemotherapy, followed by prophylactic bilateral lung radiotherapy ${ }^{(7,8)}$. After surgery and/ or radiotherapy, the treatment is consolidated with chemotherapy in order to reduce the chance of disease recurrence. For those patients with advanced stage disease and multiple metastases, chemotherapy alone is recommended.

Patients with extraosseous Ewing's sarcoma should receive the same treatment indicated for the classical Ewing's tumor, with similar therapeutic response rates. The involvement of the axial skeleton and pelvis yield a worse prognosis $^{(9)}$. Good prognosis factors include good clinical and pathological response (>90\% tumor necrosis) after chemotherapy.

CT and MRI have been utilized to evaluate the therapeutic response of Ewing's tumors. However, such methods are limited, as minute structural and morphological alterations may be observed even in tumors whose viability is significantly reduced after treatment ${ }^{(10)}$.

Based on the intensity of FDG uptake by the lesions, PET/CT allows for the detection of tumor regression and progression even before the identification of morphological alterations by anatomical imaging methods such as CT and $\mathrm{MRI}^{(11,12)}$. It is important to remind that the metabolic response precedes the volumetric decrease of the tumors.

The PET/CT findings either during or after the treatment can aid in important decision making about maintaining or modifying therapy, besides providing prognostic data. 

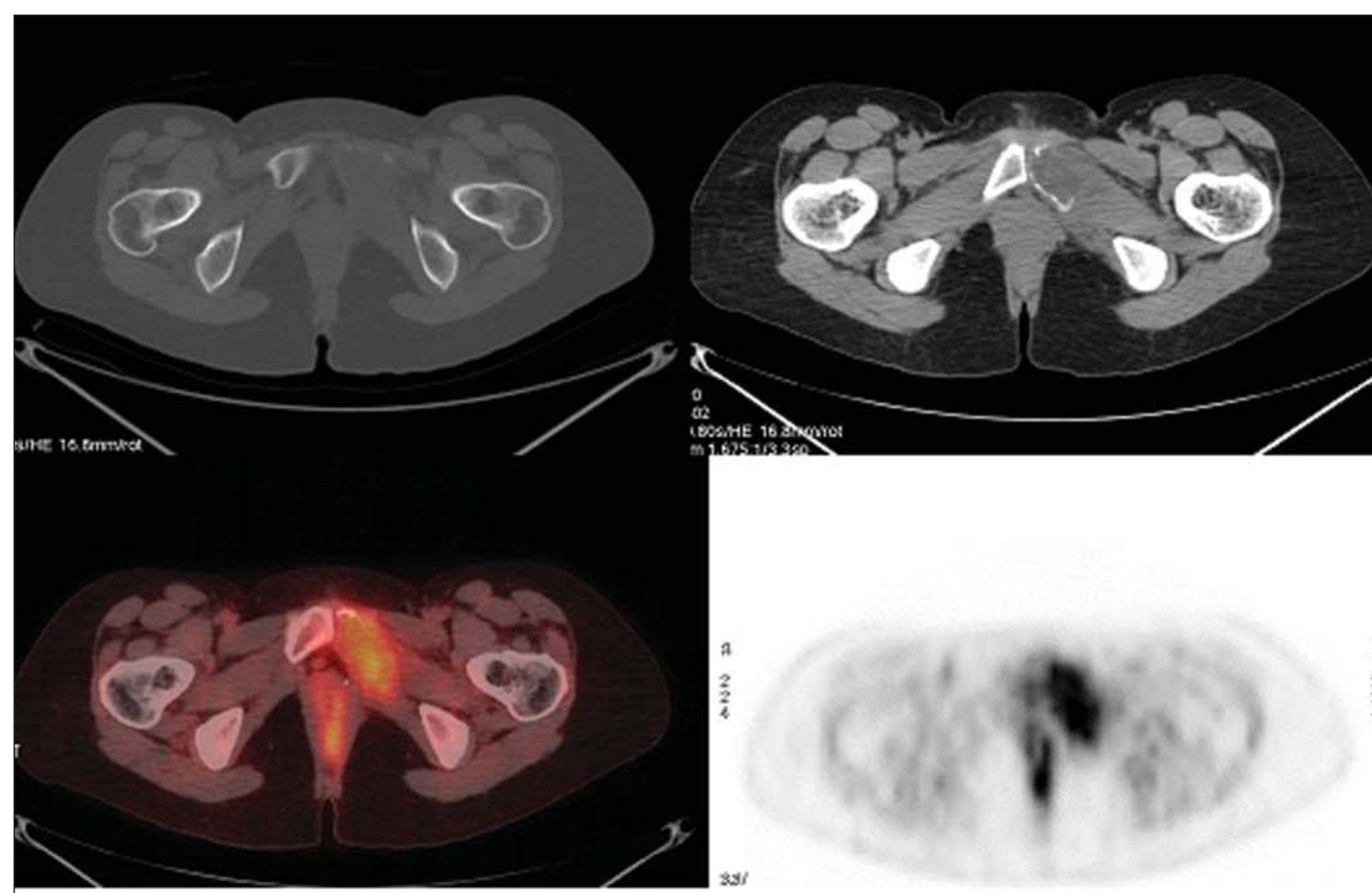

$8 x$
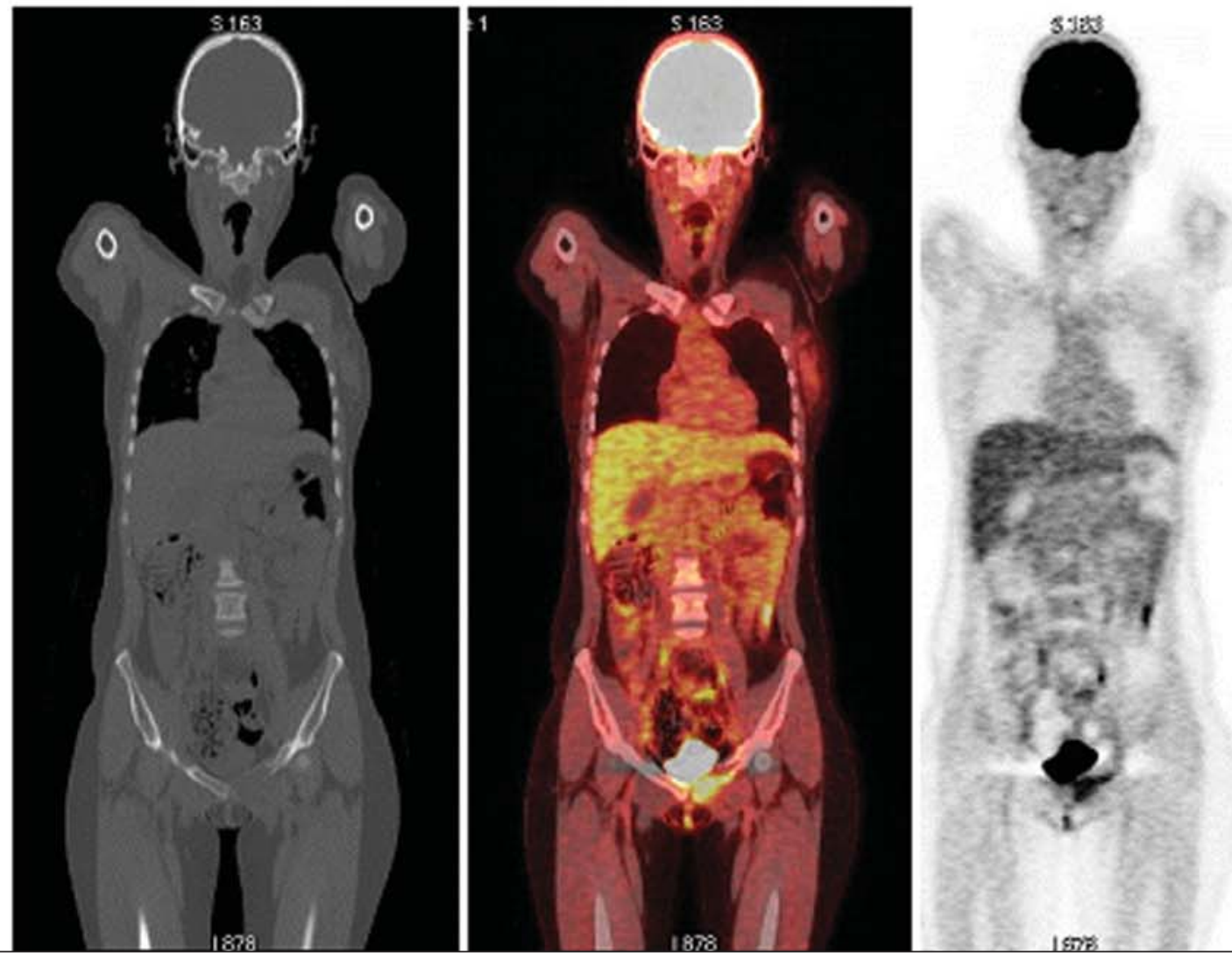

Figure 1. PET/CT image of a 13-year-old female patient diagnosed with Ewing's sarcoma. One observes expansile lytic lesion affecting particularly the left ischiopubic ramus, with rupture of the bone cortex and soft tissue components compromising the internal obturator and adductor magnus muscles, showing glycolytic hypermetabolism (SUV max $=2.1$ ). No other lesion was detected with the method. 


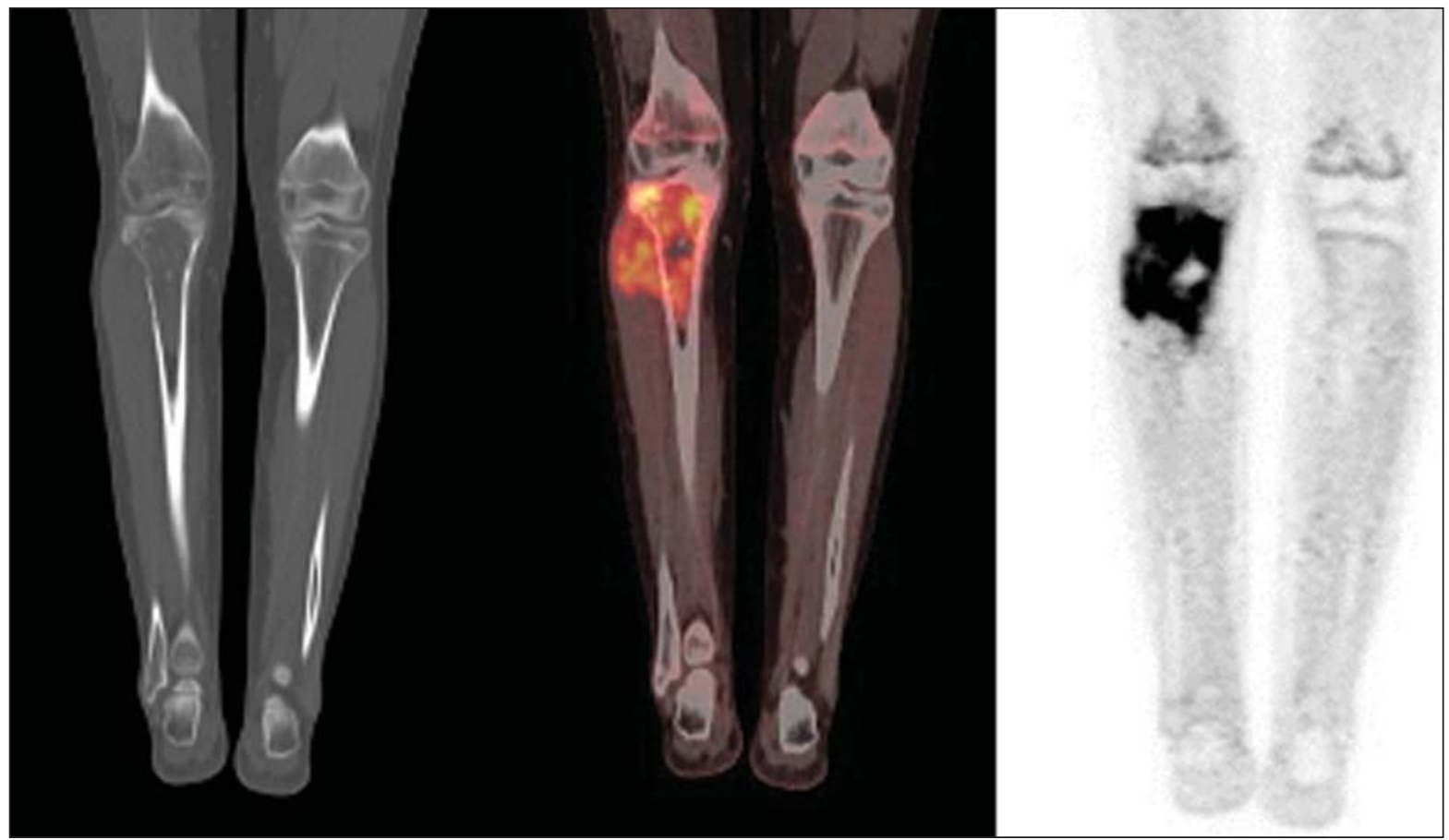

Figure 2. PET/CT image of a 15-year-old female patient diagnosed with Ewing's sarcoma. One observes a permeative, destructive lesion compromising the epiphysis, metaphysis and proximal diaphysis of the right tibia, with extraosseous extension, revealing sharp glycolytic activity (SUV max $=6.6$ ).

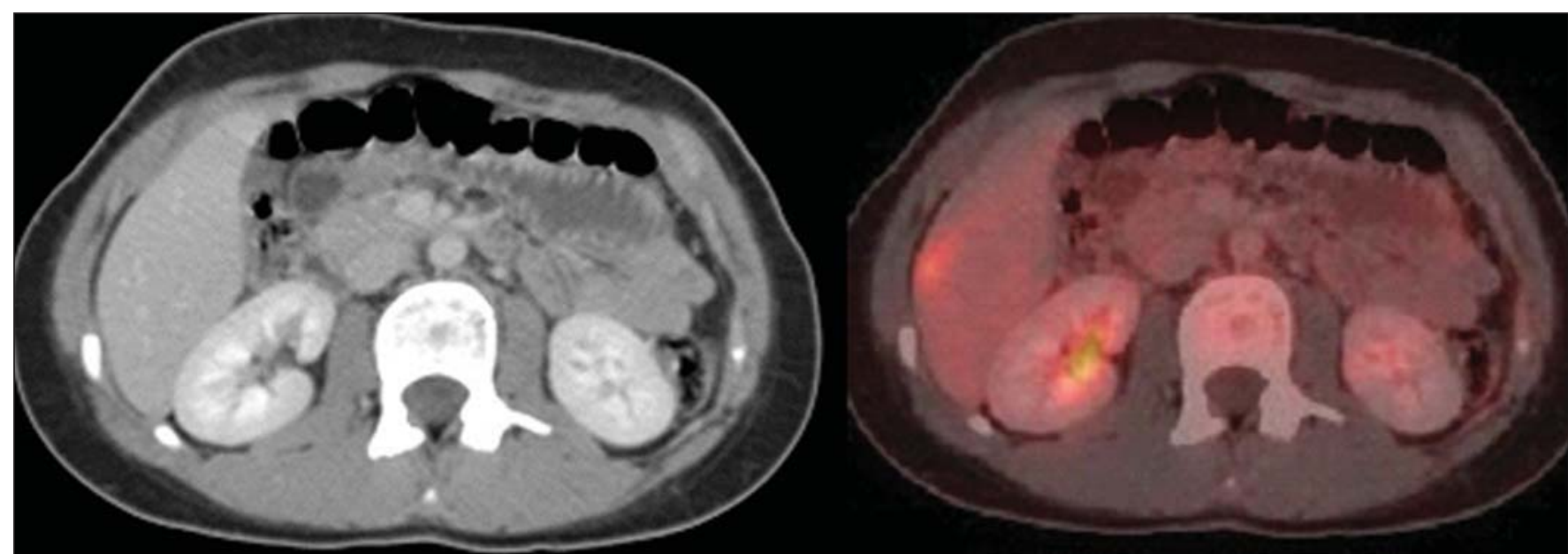

Figure 3. PET/CT and TC images of the same patient as on Figure 2 showing an area of moderate radiopharmaceutical uptake in the periphery of the VI hepatic segment, with increased radiopharmaceutical uptake at the delayed phase, with no sign of the lesion at CT. The lesion was actually a metastasis diagnosed only by PET (sharp glycolytic activity) and not by CT (anatomical). 
The method relies on the quantitative analysis of SUV as well as on visual qualitative analysis to evaluate the degree of FDG uptake by the lesion. Neoplastic tissues with $30 \%$ decrease in SUV (quantitative analysis) as compared with the baseline, i.e. pre-chemotherapy study, are classified as good responders to the instituted treatment ${ }^{(12)}$. On the other hand, a $30 \%$ increase of SUV characterizes disease progression.

Some authors also advocate that a SUV reduction to less than 2.5 after chemotherapy is associated with an increase in disease-free survival, with $79 \%$ positive predictive value for favorable response (less than $10 \%$ of viable neoplastic tissue in the lesion) ${ }^{(13)}$.

According to the above-mentioned data, PET/CT can be an excellent tool for the evaluation of therapeutic response of tumors of the Ewing's sarcoma family. However, studies with larger populations are still necessary to determine which imaging method is best, either anatomical methods such as

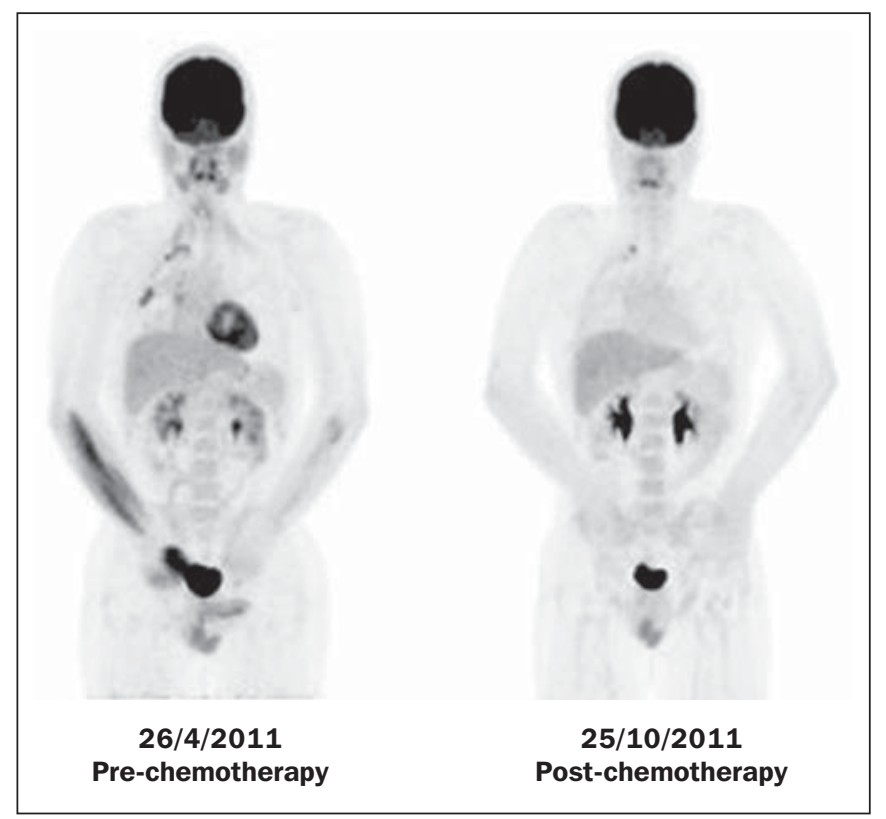

Figure 4. Pre- and post-chemotherapy PET/CT image of a 40-year-old male patient with Askin's tumor. One observes sharp reduction in FDG concentration at the expansile lesion located in the pleural plane of the right hemithorax at the postchemotherapy image, with only a small hypermetabolic area remaining at the apex.
CT and MRI (based on morphostructural changes - dimensions and tumor necrosis) or physiological methods (such as PET/CT, by means of glucose metabolism).

Figures 4 and 5 show PET/CT images of a patient with Askin's tumor.

\section{FDG-PET/CT LIMITATIONS}

PET has some disadvantages as compared with anatomical imaging methods. CT is capable of detecting small lung lesions, a fundamental factor in the treatment, as it allows for the performance of metastasectomy or radiotherapy, thus increasing patients' survival ${ }^{(3,6)}$. The metabolic characterization of small-sized lung lesions is limited, especially due to the low spatial resolution of the apparatus for lesions $<0.7$ $\mathrm{cm}^{(5)}$ that underestimates the FDG concentration. In addition, the location of nodules close to the lung bases may impair the evaluation, due to the blurring of the images and fusion failure caused by respiratory motion artifacts.

Pulmonary nodules located next to the mediastinum may be obscured by the marked glycolytic activity of the heart ${ }^{(3)}$. Also, a difference in biological behavior may occur with respect to the presence of expression of the glucose transporters expression between the primary tumor and its pulmonary metastases, which also reduces the FDG uptake by the lesions. Therefore, although PET has a high specificity for pulmonary lesions, a negative study does not rule out the presence of metastatic nodules.

A wide range of benign processes reveal glycolytic metabolism, as is the case of infectious/inflammatory diseases (tuberculosis, pneumonia, abscess, osteomyelitis, etc.), postsurgical and post-radiotherapy status, utilization of granulocyte colony-stimulating factors (promote expansion with consequential uptake by the bone marrow), among others. Inflammatory alterations secondary to surgical, traumatic or radiotherapy procedures may demonstrate glycolytic activity even three months after the event.

Benign bone lesions, such as giant cell tumors, chondroblastomas, Langerhans' cells histiocytosis, fibroxanthomas, desmoid tumors, fibrous dysplasia, among others, also reveal concentration of the radiopharmaceutical. For

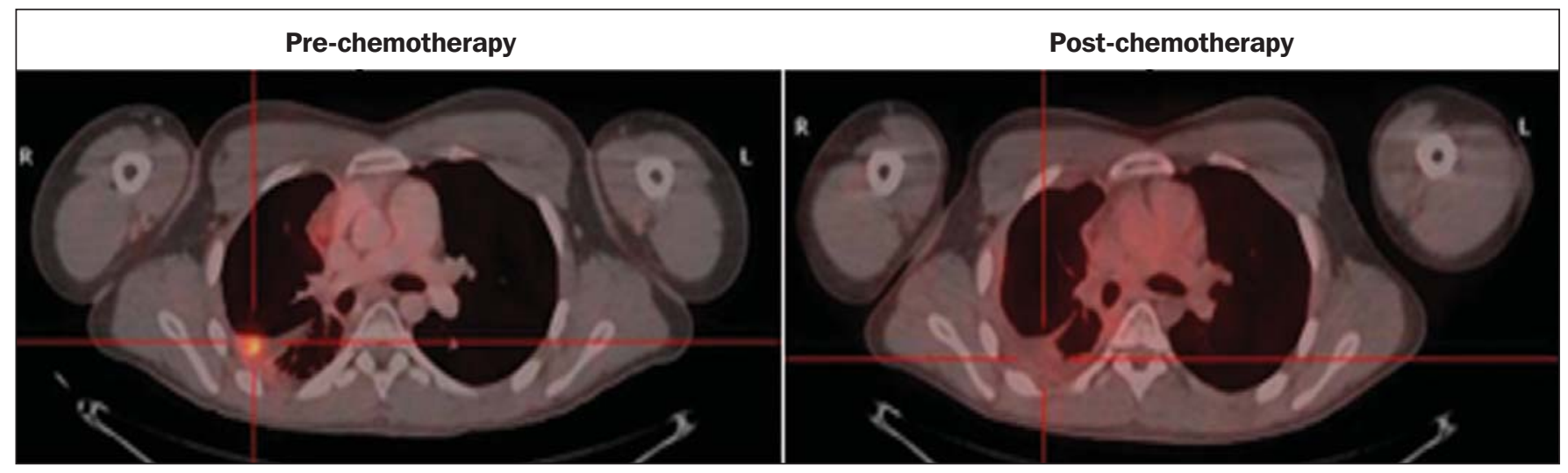

Figure 5. Pre- and post-chemotherapy PET/CT image of the same patient as on Figure 4, showing another hypermetabolic lesion in the pleural plane next to the right oblique fissure. No sign of FDG uptake is observed after chemotherapy. 


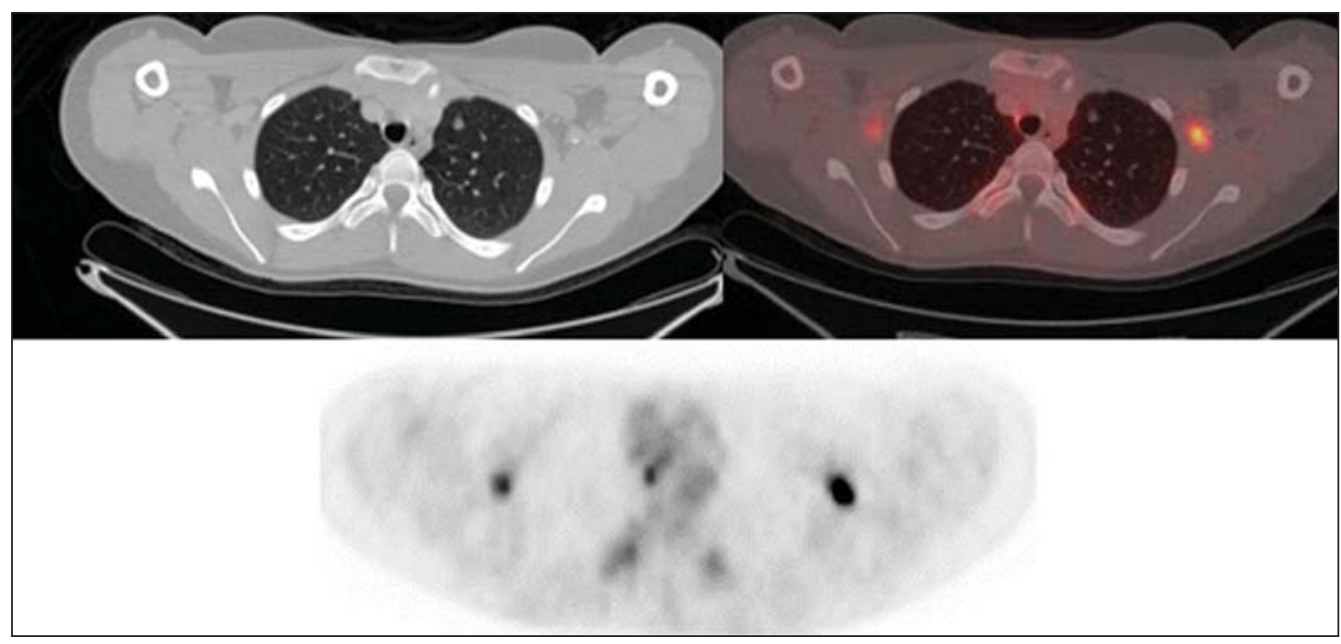

Figure 6. PET/CT and TC images of the same patient as on Figure 2, showing a pulmonary nodule with no sign of calcification, located in the upper lobe of the right lung, measuring $0.8 \mathrm{~cm}$, without radiopharmaceutical uptake. The lesion corresponded to metastasis diagnosed only at $\mathrm{CT}$, without glycolytic hyper-uptake at the PET study.

all such situations, the qualitative or quantitative analysis of SUV is of little value ${ }^{(14,15)}$. The evaluation of the tomographic characteristics of the lesions is recommended.

Figure 6 presents PET/CT and CT images of the same patient on Figure 2.

\section{CONCLUSION}

The PET/CT study became a valuable imaging method in the staging, restaging and evaluation of therapeutic response in patients with Ewing's tumor. The relevance of the method in the evaluation of such patients lies on its capability to provide additional physiological data, which many times generate relevant clinical implications, such as changes in the therapy scheme, surgical approach and treatment interruption.

However, the current evaluation of patients with Ewing's tumor should be comprehensive, including PET/CT combined with other anatomical imaging modalities such as radiography, CT and MRI.

\section{REFERENCES}

1. Ludwig JA. Ewing sarcoma: historical perspectives, current stateof-the-art, and opportunities for targeted therapy in the future. Curr Opin Oncol. 2008;20:412-8.

2. Furth C, Amthauer H, Denecke T, et al. Impact of whole-body MRI and FDG-PET on staging and assessment of therapy response in a patient with Ewing sarcoma. Pediatr Blood Cancer. 2006;47:60711.

3. Franzius C, Daldrup-Link HE, Sciuk J, et al. FDG-PET for detection of pulmonary metastases from malignant primary bone tumors: comparison with spiral CT. Ann Oncol. 2001;12:479-86.

4. Eary JF, Conrad EU, Bruckner JD, et al. Quantitative [F-18]fluorodeoxyglucose positron emission tomography in pretreatment and grading of sarcoma. Clin Cancer Res. 1998;4:1215-20.

5. Völker T, Denecke T, Steffen I, et al. Positron emission tomogra- phy for staging of pediatric sarcoma patients: results of a prospective multicenter trial. J Clin Oncol. 2007;25:5435-41.

6. Brenner W, Bohuslavizki KH, Eary JF. PET imaging of osteosarcoma. J Nucl Med. 2003;44:930-42.

7. Spunt SL, McCarville MB, Kun LE, et al. Selective use of wholelung irradiation for patients with Ewing sarcoma family tumors and pulmonary metastases at the time of diagnosis. J Pediatr Hematol Oncol. 2001;23:93-8.

8. Paulussen M, Ahrens S, Burdach S, et al. Primary metastatic (stage IV) Ewing tumor: survival analysis of 171 patients from the EICESS studies. European Intergroup Cooperative Ewing Sarcoma Studies. Ann Oncol. 1998;9:275-81.

9. Dileo P, Bertulli R, Piovesan C, et al. Long-term results with combined treatment in adult localized extraskeletal Ewing's sarcoma (ES): a retrospective analysis of 51 patients (pts) from a single referral center. J Clin Oncol. 2009;27(15S):abstr 10548.

10. McCarville MB, Christie R, Daw NC, et al. PET/CT in the evaluation of childhood sarcomas. AJR Am J Roentgenol. 2005; 184:1293304.

11. Franzius C, Sciuk J, Brinkschmidt C, et al. Evaluation of chemotherapy response in primary bone tumors with F-18 FDG positron emission tomography compared with histologically assessed tumor necrosis. Clin Nucl Med. 2000;25:874-81.

12. Bredella MA, Caputo GR, Steinbach LS. Value of FDG positron emission tomography in conjunction with MR imaging for evaluating therapy response in patients with musculoskeletal sarcomas. AJR Am J Roentgenol. 2002;179:1145-50.

13. Hawkins DS, Schuetze SM, Butrynski JE, et al. [18F]Fluorodeoxyglucose positron emission tomography predicts outcome for Ewing sarcoma family of tumors. J Clin Oncol. 2005;23:8828-34.

14. Franzius C, Daldrup-Link HE, Wagner-Bohn A, et al. FDG-PET for detection of recurrences from malignant primary bone tumors: comparison with conventional imaging. Ann Oncol. 2002;13:15760.

15. Goodin GS, Shulkin BL, Kaufman RA, et al. PET/CT characterization of fibroosseous defects in children: 18F-FDG uptake can mimic metastatic disease. AJR Am J Roentgenol. 2006;187:1 124-8. [Published correction appears in AJR Am J Roentgenol. 2006; 187:1146]. 